\title{
Optimization of Economic Load Dispatch Problem by Using Particle Swarm Optimization Technique-A Review
}

\author{
Ajay Nagar ${ }^{1}$, Dhawal Sethi ${ }^{2}$ \\ ${ }^{1}$ PG Scholar, Oriental University, Department of Electrical and Electronics Engineering, Sanver Road, Indore 453555, India \\ ${ }^{2}$ Assistant Professor, Oriental University, Department of Electrical and Electronics Engineering, Sanver Road, Indore 453555, India
}

\begin{abstract}
The economic load dispatch plays a crucial role in the operation of the power grid. The unit commitment or pre-dispatch is the first problem, to satisfy the expected load and supply a specified margin of operational reserve over a specified amount of your time and second side of economic dispatch is that the online economic dispatch, whereby it's needed to distribute the load amongst offered generating units paralleled with the system in such a way. In this practice to optimize the load dispatch at minimum cost there is to work is going on like Genetic algorithm, artificial bee colony, bat algorithm, lambda iteration etc. this paper used particle swarm optimization techniques to obtain the optimized solution of economic dispatch. In this paper, we study different cases to find the suitable solution for Economic load dispatch.
\end{abstract}

Keywords: Economic load dispatch, Particle swarm optimization, Genetic algorithm, cost minimization, power system.

\section{Introduction}

Economic load dispatch (ELD) is a very important improvement task in grid operation for allocating generation among the committed units such the constraints obligatory square measure glad and, therefore, the energy needs in terms of British thermal units per hour $(\mathrm{Btu} / \mathrm{h})$ or dollar per hour $(\$ / h)$ square measure decreased. A tiny low saving within the operation of the generating system results in a big reduction in the disbursement of the facility plant. The most objective of the economic load dispatch of generating systems is to attain minimum disbursement of a thermal powerhouse. The world total energy annual consumption generally increases.

A listing survey on ELD ways reveals that numerous numerical improvement techniques are used to get the answer of the ELD drawback. ELD drawback solved historically victimization mathematical programming supported improvement techniques like Particle Swarm improvement (PSO) with valve purpose result and its variants i.e. Self-Organizing gradable Particle Swarm improvement [2][3], Hybrid Particle Swarm improvement Approach [4], Quantum-Inspired Particle Swarm improvement (PSO) with valve loading [5] and microorganism hunt improvement based Dynamic with nonsmooth value performance [6].

ELD drawback is aimed to optimize the disbursement of the facility system whereas satisfying numerous systems in operation constraints. The electrical power trade is restructured around the world to fulfill the growing load demand. Most of the facility transfer is distributed through wheeling transactions within the restructured power market. ELD used a robust assistant tool in each designing and in operation stage.

\section{Problem Formulation}

The main goal of this work is to get a selected set of points of ELD drawback, together with all outputs of the ability generation units, such all equality and difference constraints are glad.

The ELD problem objective function is formulated mathematically in (1) and (2),

$$
\begin{aligned}
& \mathrm{F}_{\mathrm{T}}=\operatorname{Min} \mathrm{f}(\mathrm{FC}) \\
& \mathrm{FC}=\sum_{\mathrm{i}=1}^{\mathrm{n}} \mathrm{a}_{\mathrm{i}} \quad \mathrm{i}^{2}+\mathrm{b}_{\mathrm{i}} \quad \mathrm{i}+\mathrm{c}_{\mathrm{i}}
\end{aligned}
$$

Where, is the main objective function, $a_{i}, b_{i}$ and $c_{i}$ are the cost coefficients.

\subsection{Economic cost functions with valve-point effect}

The generating units with multiple valves in steam turbines square measure out there. The gap and shutting off those valves square measure useful to take care of the active power balance but it adds the ripples within the price perform as shown in Fig.1 that makes the target perform extremely nonlinear.

The sinusoidal functions are added to the quadratic cost function as given in equation (3).

$\left.\mathrm{FC}_{\mathrm{i}} \mathrm{C}_{\mathrm{i}}\right)=\mathrm{a}_{\mathrm{i} \mathrm{i}^{2}}+\mathrm{b}_{\mathrm{i} i \mathrm{i}}+\mathrm{c}_{\mathrm{i}}+\operatorname{abs}\left(\mathrm{e}_{\mathrm{i}} \sin \left(\mathrm{f}_{\mathrm{i}}\left(\mathrm{i}_{\mathrm{i}}^{\min }-{ }_{\mathrm{i}}\right)\right)\right)$

Where $e_{i} \& f_{i}$ are the coefficients of generator i considering valve-point loading effect, 


\section{International Journal of Science and Research (IJSR) \\ ISSN (Online): 2319-7064}

Index Copernicus Value (2013): 6.14 | Impact Factor (2014): 5.611

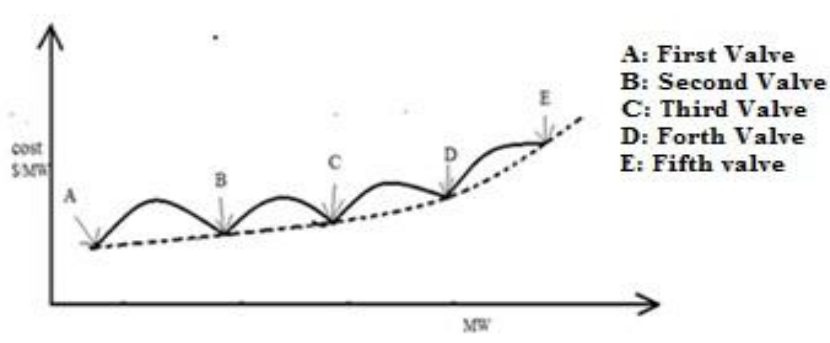

Figure 1: Incremental fuel cost curve for five valve steam turbine units

\section{Constraints}

This model is subjected to the following constraints,

1) Power Balance Equation

For power balance, an equality constraint should be satisfied. The total generated power should be equal to total load demand plus the total losses,

$$
\sum_{\mathrm{i}=1}^{\mathrm{n}} \quad \mathrm{i} \quad \mathrm{D} \quad \mathrm{L}
$$

Where, $\mathrm{P}_{\mathrm{D}}$ is the total system demand and $\mathrm{P}_{\mathrm{L}}$ is the total line loss.

\section{2). Power Generation Limits}

There is a limit on the amount of power which a unit can deliver. The power output of any unit should not exceed its rating nor should it be below that necessary for stable operation. Generation output of each unit should lie between maximum and minimum limits.

$$
P_{i}^{\min } \leq{ }_{\mathrm{i}} \leq P_{i}^{\max }
$$

Where, $\mathrm{Pi}$ is the output power of $\mathrm{i}_{\text {th }}$ generator,

$i$, min And $i, \max$ are the minimum and maximum power outputs of generator i respectively.

\section{Optimization Methods for ELD}

In the present scenario, there is many techniques are available to obtain the solution for economic load dispatch. Optimization may be a procedure of finding and scrutiny possible resolutions unless best solution has been found. Varied improvement technique, typical and nonconventional square measure shown in Fig. 2.

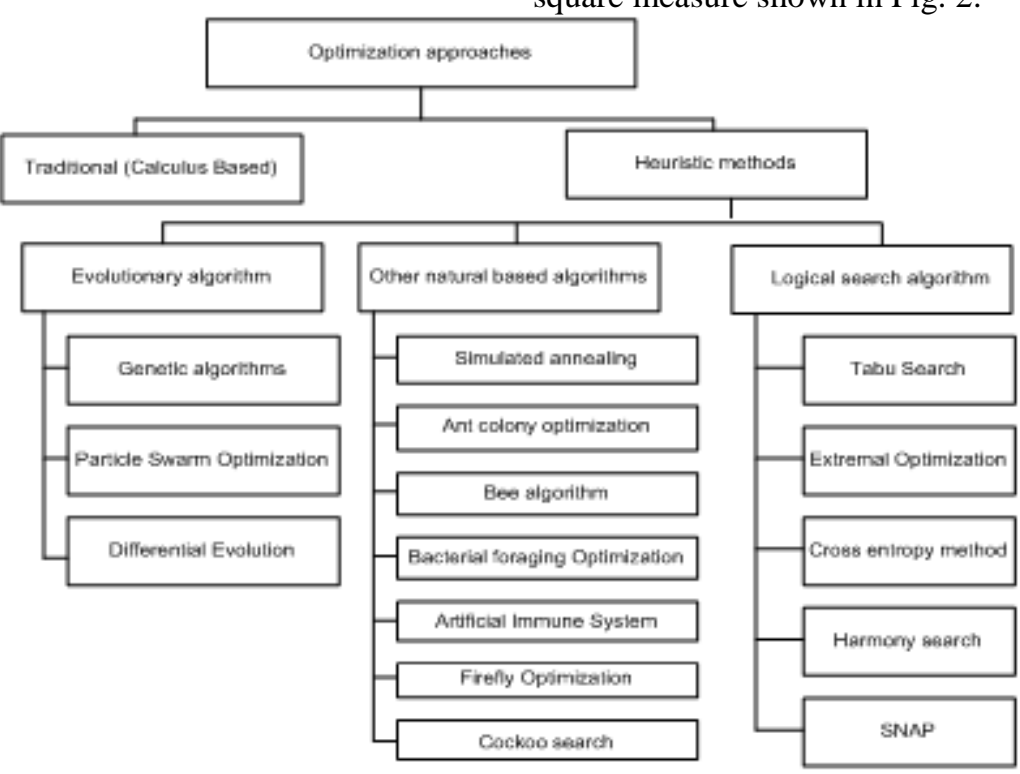

Figure 2: Different optimization technique

Some of the common techniques are listed below.
a) Genetic algorithm
b) Quadratic programming
c) Lambda iteration technique
d) Artificial bee colony
e) Bat algorithm
f) Particle swarm optimization
g) Tabu search
h) Firefly optimization
i) Simulated annealing
j) Harmony search
k) SNAP

\section{Particle Swarm Optimization}

The basic PSO is developed by Kennedy and Eberhart in 1995, Eberhart, Simpson, and Dobbins in 1996, Russell C. Eberhart and Yuhui Shi in 2001.The original intent was to diagrammatically simulate the sleek, however, an unpredictable choreography of a bird flock. The PSO is meta-heuristic naturally inspired population-based evolutionary technique which is considered as an algorithm to solve ELD problems. The detailed implementation steps of PSO are as follows:

\section{Step1: Initialize swarm size}

Initialize a population of particles with random positions and velocities on d dimensions within the downside area.

\section{Step2: Evaluate Fitness}

For each particle, evaluate the required optimization fitness operate in d variables.

Step3: Compare particle's fitness analysis with particle's pbest; If the current price is best than pbest, then set pbest price adequate to the present price, and also the pbest location 


\section{International Journal of Science and Research (IJSR) \\ ISSN (Online): 2319-7064 \\ Index Copernicus Value (2013): 6.14 | Impact Factor (2014): 5.611}

adequate to the present location in the d-dimensional area.

Step4: Compare fitness analysis with the population's overall previous best;

If the current price is best than gbest, then reset gbest to the present particles array index and price.

Step5: amendment the speed of the particle in keeping with equation (6)

$$
\begin{aligned}
& \mathrm{V}_{\mathrm{i}}^{(\mathrm{K}+1)}=\mathrm{WV}_{\mathrm{i}}^{\mathrm{K}}+\mathrm{c}_{1} \operatorname{Rand}_{1} \quad\left(\text { 제? } \mathrm{S}_{\mathrm{i}}^{\mathrm{K}}\right)+\mathrm{c}_{2} \operatorname{Rand}_{2} \\
& \text { (?]?]??- } \mathrm{S}_{\mathrm{i}}^{\mathrm{K}} \text { ) }
\end{aligned}
$$

Where $V_{i}^{(K+1)}$ is the particle velocity at current iteration $(\mathrm{k}+1)$

$\mathrm{V}_{\mathrm{i}}^{\mathrm{K}}$ is the particle velocity at iteration $\mathrm{k}$

$r_{1}$ and $r_{2}$ Are random numbers between $[0,1]$ and

$\mathrm{c}_{1}$ and $\mathrm{c}_{2}$ Are acceleration constant

The acceleration constants $\mathrm{c} 1$ and $\mathrm{c} 2$ in equation (6) represent the coefficient of the random acceleration terms that pull every particle toward pbest and gbest positions. c1 and c2 every up to two for nearly all applications. Speed Vmax was, therefore, the sole parameter we regularly set it at regarding $10-20 \%$ of the dynamic vary of the variable on every dimension.

Step6: modification the position of the particle according to equation (7)

$$
S_{i}^{(K+1)}=S_{i}^{K}+V_{i}^{K+1}
$$

Where, $S_{i}^{(K+1)}$ is the current particle position at iteration $k+1$ $\mathrm{S}_{\mathrm{i}}^{\mathrm{K}} \quad$ is the current particle position at iteration $\mathrm{k}$.

Step7: Loop to step two till a criterion is met,

Typically a spare sensible fitness or a most range of iterations (generations).

\section{Literature Reviews for PSO in ELD}

The ELD method is connected for allotting power era amongst conferred producing units so that the aggregate era expenses of the framework and transmission misfortunes are additionally minimized. In all pragmatic force frameworks, minimizing the aggregate operation expense is imperative. Part of scientists received distinctive routine and nonordinary strategies to streamline the above issue. Because of the unpredictability in nature of the streamlining issue, developmental calculation strategies, particularly PSO has picked up notoriety to take care of monetary burden dispatch issue. Here nitty gritty writing survey in the branch of knowledge is given beneath:

Adel Ali Abou et al.[1] discovered Molecule Swarm Optimization technique. It depends on neighborhood extremum escape. Another definition has been known as the most exceedingly terrible position. Much of the time of improvement issues, don't have a clue about the extent that answer is that. In the aftereffects of inspecting on the benchmark capacities have been watched that when the statement is not in the scope of the answer, the other known techniques are caught in nearby compelling. The technique displayed is equipped for going through it and the outcomes have been accomplished with higher precision.

Dixit Gaurav Prasad et al. [2] discussed the element financial dispatch utilizing Artificial Bee Colony calculation for producing units with Valve-Point stacking impact. The attainability of the proposed technique is approved with 10 and 5 unit test frameworks for a time of 24 hours. Results acquired with the proposed methodology are contrasted and different strategies.

A. Jaini et al. [3] had introduced a PSO procedure for financial burden dispatch of benchmarks test framework IEEE 26-BUS.The results uncovered that the proposed method has merit in accomplishing ideal answer for tending to of untimely joining.

Hong-Gang Wang et al. [4], presented a paper on QuantumInspired Particle Swarm Optimization (QPSO) system proposed by which has more grounded hunt capacity and faster-merging pace, not just in view of the presentation of quantum processing hypothesis, additionally because of two uncommon usages: self-versatile likelihood determination and disordered groupings change. Examinations with comparable methodologies including the developmental programming (EP), PSO are given.

Wang xiao-hua et al. [5] displayed an improvement approach in which Hybrid Particle Swarm Optimization Combined Simulated Annealing Method (HPSAO) for monetary burden dispatch. Here Simulated Annealing (SA) calculation is utilized to help PSO, to bounce out the nearby ideal. Besides, a practicality based guideline is acquainted with manage the requirements.

XinMA et al. [6] proposed the dynamic burden monetary dispatch model consider the turning hold in power market and after that, an Improved Particle Swarm calculation is put up to fathom them. A framework including 15 producing units is considered and the ideal consequences of IPSO and PSO are looked at.

Wu Yunna et al. [7] introduced another technique for EELD issue the ANN blended with the innovation of trust district with input control to tackle financial burden dispatch issues. The outcomes demonstrate that the new calculation has the better worldwide merging as well as the higher concurrent pace.

Abido M. A [8], described Another Multi-Objective MetaHeuristics (MOMH) strategy that comprises of cutting edge Multi-Objective Evolutionary Particle Swarm Optimization (Advanced MOEPSO) for Multi-Objective Economic Load Dispatching (MOELD) with regards to the natural safeguarding in force systems. The proposed technique is effectively connected to the 39-hub 10-unit framework.

Panigrahi B.K et al. [9] displayed a heuristic improvement approach, bacterial scavenging and A Bacterial Foraging 


\section{International Journal of Science and Research (IJSR) \\ ISSN (Online): 2319-7064 \\ Index Copernicus Value (2013): 6.14 | Impact Factor (2014): 5.611}

Particle Swarm Optimization-Differential Evolution (BPSODE) for fathoming Non-Convex Dynamic Economic Dispatch issue (DED). The proposed technique accomplishes worldwide expense by selecting the bacterium with great scavenging procedures. The microscopic organisms with great rummaging methodologies are acquired in the redesigning procedure of each chemo-strategy venture by the PSO administrator and the DE administrator adjusts the arrangement got through bacterial scavenging and PSO calculation. An IEEE 39-bus, 10 unit New-England test frameworks is considered to Show the adequacy of the proposed system over other existing routines.

Ting-Fang YU et al. [10] developed An Improved Particle Swarm Optimization exhibited for taking care of the issue of the untimely union in PSO. An Improved PSO with the requirements in part unraveled joined with punishment capacity.

K. Vaisakh et al. [11] talked about the ideal mix of force yields for all creating units over a specific timeframe so as to minimize the aggregate fuel cost, while fulfilling dynamic operational imperatives and load request in every interim. As of late social searching conduct of Escherichia coli microbes has been investigated to add to a novel calculation for dispersed improvement and control.

Aniruddha Bhattacharya et al. [12] proposed a novel Particle Swarm Optimizer joined with Roulette determination administrator, to understand the monetary burden dispatch (ELD) issue of warm generators of a force framework. A few elements, for example, quadratic expense capacities with valve point stacking, transmission misfortune, generator incline rate confines and precluded working zone are considered in the calculation models.

Zaraki Abolfazl et al. [13] proposed another PSO strategy to decide the yielding power, while fulfilling all requirements of the greater part of the force era units, so that the cost capacity is minimized. In this paper, a piecewise quadratic capacity is utilized to demonstrate the fuel cost mathematical statement of every era units and the Bcoefficient grid is utilized to speak to transmission misfortunes. Results acquired by proposed technique are ordinarily contrasted and the outcomes got by GA and QP.

Vlachogiannis John et al. [14] introduced An Improved Coordinated Aggregation based Particle Swarm Optimization (ICA-PSO) calculation for settling the ideal Economic Load Dispatch (ELD) issue. In the ICA-PSO calculation, every molecule in the swarm holds a memory of its best position ever experienced and is pulled in just by different particles with preferred accomplishments over its own particular except for the molecule with the best accomplishment, which moves arbitrarily.

\section{Conclusion}

In this paper, we studied different approaches to find the optimum solution with different methods And included the most relevant paper of related to optimization and simulation by the result of review we determine particle swarm optimization technique is fast in convergence to find the optimum solution. The proposed method is tested on standard data given in different research paper.

\section{References}

[1] A Adel Ali Abou EL-Ela and Ragab Abdel-Aziz EISehiemy, "Optimized generation cost using modified particle swarm optimization version," WSEAS transactions on power systems, pp. 225-232, October2007.

[2] Dixit Gaurav Prasad, Dubey Hari Mohan and Pandit Manjaree, Economic load dispatch using artificial bee colony optimization", International conference on advanced computing, communication, and networks 11 , pp. 620-625, 2011.

[3] Jaini A., Musirin I., Aminudin N., Othman M. M. and Rahman T. K. A, Particle swarm optimization technique in economic power dispatch problems", the 4th international power engineering and optimization conf., Malaysia, pp. 308-313, 23-24 June 2010.

[4] Meng Ke, Wang Hong Gang, ZhaoYang Dong and Wong Kit Po, Quantum-Inspired particle swarm optimization for valve-point economic load dispatch", IEEE transactions on power systems, vol. 25, no.1, pp. 215-221, February 2010.

[5] Wang xiao-hua and Zhang yong mei, Ehaotic quantum-behaved PSO algorithm for power system economic load dispatch", International journal of digital content technology and its applications, vol.5, number 8, pp. 290-297, August 2011.

[6] XinMA and Yong LIU, Particle swarm optimization to solving economic load dispatch with spinning reserve", IEEE conference on computer design and applications, pp. 214-217, 2010.

[7] Wu Yunna and Li Cong, "A new method for EELD problem the ANN harmonized with a technology of trust region", IEEE conference, pp. 1-6, 2009

[8] Abido M. A., Multiobjective evolutionary algorithms for electric power dispatch problem", IEEE transactions on evolutionary computation, vol. 10, no. 3, pp. 315329, June 2006.

[9] Panigrahi B.K. and Pandi V. Ravikumar, "Bacterial foraging optimization: Nelder-Mead hybrid algorithm for economic load dispatch", IET generation transmission distribution, vol. 2, no. 4, pp. 556-565, 2008.

[10] Ting-Fang YU and Chun-Hua PENG, Application of an Improved particle swarm optimization to economic load dispatch in power plant", 3rd IEEE conference on advanced computer theory and engineering, pp. 619624, 2010.

[11] Vaisakh K. and Srinivas L.R., Đifferential approach for optimal power flow solutions," Journals of theoretical and applied information technology, pp. 261-268, 2005-08.

[12] Bhattacharya Aniruddha and Chattopadhyay Pranab Kumar, -Amodified particle swarm optimization for solving the non-convex economic dispatch", IEEE conference, pp. 1-4, 2009.

[13] Zaraki Abolfazl and Othman Mohd Fauzi Bin, Implementing particle swarm optimization to solve economic load dispatch problem", IEEE international 


\section{International Journal of Science and Research (IJSR) \\ ISSN (Online): 2319-7064}

Index Copernicus Value (2013): 6.14 | Impact Factor (2014): 5.611

conference on soft computing and pattern recognition, pp. 60-65, 2009.

[14] Vlachogiannis John G. and Kwang Y. Lee, Economic load dispatch-A comparative study on heuristic optimization techniques with an improved coordinated aggregation-based PSO", IEEE transactions on power systems, vol. 24, no. 2, pp. 991-1001, May 2009.

\section{Author Profile}

A Ajay Nagar, received the BE degree in electrical and electronics engineering from RGPV university (M.P.) India in 2010. He is Pursuing Master of Technology in electrical power system from Oriental University, Indore (M.P.) India under supervision of Mr. Dhawal Sethi.

Mr. Dhawal Sethi, is working in department of Electrical and Electronics Engineering from Oriental University, Indore (M.P.) India. His research area is Cost Analysis in electrical power system, Optimization of hybrid electric generation. 